\section{LRRK2 Phosphorylation: Behind the Scenes}

The Neuroscientist

$1-15$

(C) The Author(s) 2018

Reprints and permissions:

sagepub.com/journalsPermissions.nav DOI: $10.1|77 / 10738584| 8756309$ journals.sagepub.com/home/nro

(S)AGE

\author{
Tina De Wit', Veerle Baekelandt', and Evy Lobbestael'
}

\begin{abstract}
Mutations in the gene encoding leucine-rich repeat kinase 2 (LRRK2) are known today as the most common genetic cause of Parkinson's disease (PD). LRRK2 is a large protein that is hypothesized to regulate other proteins as a scaffold in downstream signaling pathways. This is supported by the multiple domain composition of LRRK2 with several protein-protein interaction domains combined with kinase and GTPase activity. LRRK2 is highly phosphorylated at sites that are strictly controlled by upstream regulators, including its own kinase domain. In cultured cells, most pathogenic mutants display increased autophosphorylation at SI292, but decreased phosphorylation at sites controlled by other kinases. We only begin to understand how LRRK2 phosphorylation is regulated and how this impacts its physiological and pathological function. Intriguingly, LRRK2 kinase inhibition, currently one of the most prevailing disease-modifying therapeutic strategies for PD, induces LRRK2 dephosphorylation at sites that are also dephosphorylated in pathogenic variants. In addition, LRRK2 kinase inhibition can induce LRRK2 protein degradation, which might be related to the observed inhibitor-induced adverse effects on the lung in rodents and non-human primates, as it resembles the lung pathology in LRRK2 knock-out animals. In this review, we will provide an overview of how LRRK2 phosphorylation is regulated and how this complex regulation relates to several molecular and cellular features of LRRK2.
\end{abstract}

\title{
Keywords
}

Parkinson's disease, LRRK2, phosphorylation, kinase inhibition

\section{Introduction}

\section{Parkinson's Disease}

Parkinson's disease (PD) is the second most common neurodegenerative disorder after Alzheimer's disease and the most common movement disorder. Current treatment options are symptomatic and thus unable to reverse or slow down disease progression. PD is recognized by several key aspects of which the primary and most predominant feature is the progressive degeneration of dopaminergic neurons in the substantia nigra pars compacta $(\mathrm{SNpc})$ (Connolly and Lang 2014; Lang and Lozano 1998). A second key feature is the presence of Lewy bodies (LBs); intraneuronal, eosinophilic inclusion bodies that mainly consist of phosphorylated and ubiquitinated $\alpha$-synuclein (Beyer and others 2009), a key protein in the pathogenesis of PD (Polymeropoulos and others 1997). PD patients typically suffer from four cardinal motor symptoms (tremor, bradykinesia, muscle rigidity, and postural instability), which manifest at the point of $70 \%$ dopaminergic neuronal cell death in the SNpc (Lang and Lozano 1998). In addition, non-motor related brain regions become affected, which results in symptoms, including cognitive and sensory decline, depression, apathy, behavioral and psychiatric issues and dysautonomia (Poewe 2008). As age is the greatest risk factor for developing PD, the incidence of PD increases with age from $1 \%$ to $2 \%$ of people older than 60 years to up till $4 \%$ of people older than 80 years (Lang and Lozano 1998). The majority of PD cases are considered idiopathic; however, in $10 \%$ of the patients a genetic cause underlies the disease (Thomas and Beal 2007). More than 40 PD risk loci have already been identified (Chang and others 2017), including the PARK8 locus, in which leucine-rich repeat kinase 2 (LRRK2) was identified as PD risk gene (Paisán-Ruíz and others 2004; Zimprich and others 2004).

\section{LRRK2 in Parkinson's Disease}

More than a decade ago, missense mutations in the gene encoding LRRK2 were identified as the cause of inherited

'Laboratory for Neurobiology and Gene Therapy, Department of Neurosciences, KU Leuven, Leuven, Belgium

\section{Corresponding Author:}

Evy Lobbestael, Laboratory for Neurobiology and Gene Therapy, Department of Neurosciences, KU Leuven, Kapucijnenvoer 33, VCTB+5, Leuven, 3000, Belgium.

Email: evy.lobbestael@kuleuven.be 


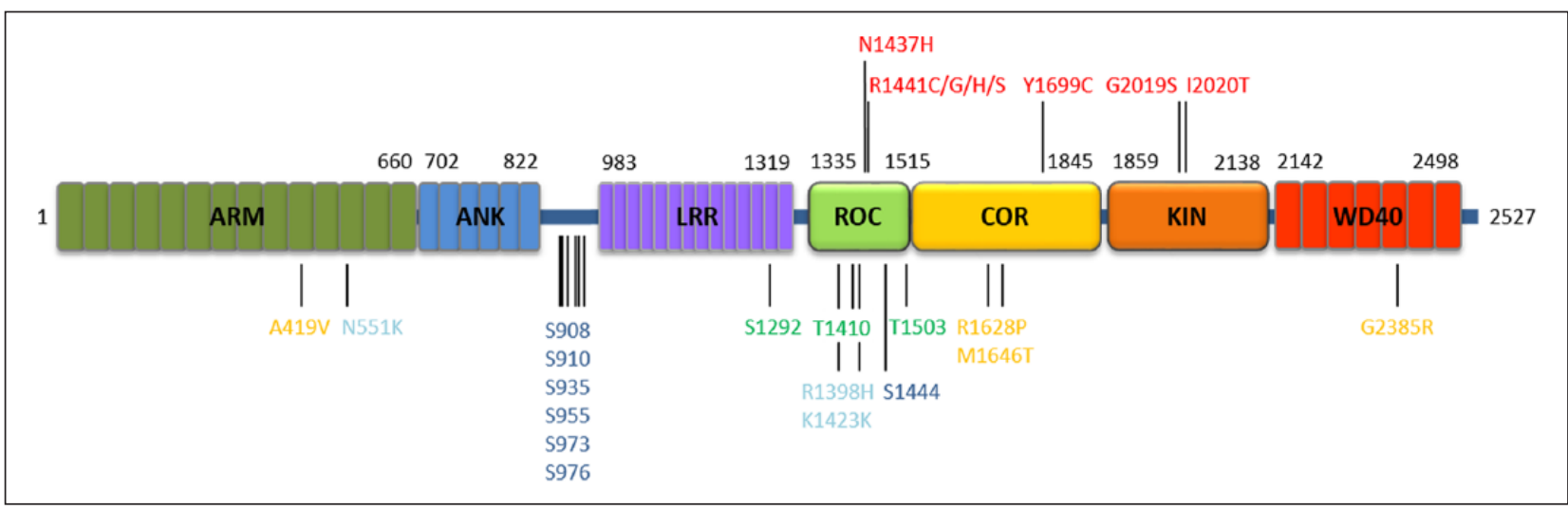

Figure I. Schematic representation of leucine-rich repeat kinase 2 (LRRK2) with domain boundaries indicated. Pathogenic mutations are depicted in red and risk factors in orange. The protective haplotype N55IK-R I398H-KI423K is indicated in light blue. Autophosphorylation sites that are validated in cells (TI4I0, TI503) or in vivo (SI292) are depicted in green. The most studied constitutive phosphorylation sites are depicted in dark blue. An overview of other LRRK2 auto- and constitutive phosphorylation sites can be found in (Lobbestael and others 20I2).

autosomal dominant PD. LRRK2 is now known as the most common gene linked to PD (Paisán-Ruíz and others 2004; Zimprich and others 2004; Di Fonzo and others 2005). Although heterozygous mutations in the gene encoding glucocerebrosidase (GBA) are more frequent, they are considered to be genetic risk factors rather than a genetic cause of PD (Clark and others 2005; Sidransky and Lopez 2012). More than 40 mutations in LRRK2 have been described, of which eight (N1437H, R1441C/G/H/S, Y1699C, G2019S, and I2020T) cause PD (Healy and others 2008a; Mata and others 2016) and four (A419V, R1628P, M1646T and G2385R) are considered risk factors as they significantly increase the risk to develop PD (Farrer and others 2007; Heckman and others 2013; Li and others 2015; Ross and others 2008; Ross and others 2011; Tan and others 2010). Interestingly, LRRK2 N551K, $\mathrm{R} 1398 \mathrm{H}$, and $\mathrm{K} 1423 \mathrm{~K}$ are identified as a protective haplotype (Heckman and others 2013; Ross and others 2011; Tan and others 2010) (Fig. 1). Worldwide, the most common pathogenic mutation, G2019S, accounts for $4 \%$ of familial PD cases and $1 \%$ of apparent sporadic PD cases (Healy and others 2008a). Interestingly, large ethnic differences exist; while the G2019S mutation is rather rare in Asian populations, it accounts for up to $40 \%$ of all PD cases in North African Arabs and Ashkenazi Jews (Lesage and others 2006; Ozelius and others 2006). In addition, genome-wide association studies have revealed that variations in the LRRK2 locus can increase the risk to develop sporadic PD (Lill and others 2012; Nalls and others 2014; Ross and others 2011; Satake and others 2009; SimónSánchez and others 2009). Interestingly, LRRK2-PD patients are clinicopathologically indistinguishable from idiopathic PD patients, suggesting that a common pathological mechanism underlies both forms of the disease
(Haugarvoll and others 2008; Haugarvoll and Wszolek 2009; Healy and others 2008b; Ishihara and others 2006; Papapetropoulos and others 2006; Smith and others 2006). Taken together, LRRK2 is a key player in PD and one of the most attractive candidates when it comes to diseasemodifying targets. Therefore, understanding LRRK2 (dys)function will be fundamental to develop therapies that cure, stop, or at least delay PD progression. Although LRRK2 has already been associated with a multitude of cellular functions such as mitochondrial function (Wang and others 2016), microtubule function (Esteves and Cardoso 2017; Blanca Ramírez and others 2017a), translation (Dorval and Hébert 2012), vesicular trafficking (Dihanich and Manzoni 2011), autophagy (Esteves and Cardoso 2017; Manzoni 2017; Wang and others 2016) and neuroinflammation (Lee and others 2017), its general physiological function and corresponding role in PD remain poorly understood.

\section{LRRK2 Kinase Activity and Inhibition}

All pathogenic mutations of LRRK2 are located in the catalytic core of the protein, which consists of a GTPase domain called ROC (Ras of complex proteins), linked to a COR-domain (C-terminal of ROC), and a kinase domain (Mata and others 2006) (Fig. 1). Clustering of disease-causing mutations at these domains suggests a role for altered enzymatic function in PD pathogenesis. Initial in vitro kinase assays were based on LRRK2 autophosphorylation or the phosphorylation of a generic (peptide) substrate and only showed a consistent increase in kinase activity for the G2019S mutation (Greggio and Cookson 2009; Jaleel and others 2007; Nichols and others 2010; West and others 2005). However, more recent 
studies assessed kinase activity in a cellular context by using a phosphospecific LRRK2 antibody that recognizes the autophosphorylation site S1292. In contrast to the in vitro studies, increased autophosphorylation at S1292 could be detected in cultured cells for most of the pathogenic mutations $(\mathrm{N} 1437 \mathrm{H}, \mathrm{R} 1441 \mathrm{C} / \mathrm{G} / \mathrm{H}, \mathrm{Y} 1699 \mathrm{C}$, G2019S, and I2020T), in brain lysates of BAC transgenic mice overexpressing LRRK2 G2019S (Reynolds and others 2014; Sheng and others 2012; Steger and others 2016) and very recently also in the striatum of G2019S knock-in mice with endogenous levels of LRRK2 protein (Longo and others 2017). Interestingly, also in idiopathic PD patients, increased autophosphorylation on S1292 has been reported in urinary exosomes (Fraser and others 2016a; Fraser and others 2016b). Several studies have now shown that increased LRRK2 kinase activity is linked to cellular toxicity in cell culture models (Greggio and others 2006; Smith and others 2006) and in vivo (Daher and others 2015; Lee and others 2010a; Yao and others 2013). Increased levels of cell death induced by overexpression of pathogenic LRRK2 variants could be avoided when introducing a mutation that abolishes kinase activity; for example, after transfecting cultured cells or primary cortical neurons (Greggio and others 2006; Lee and others 2010a; Lee and others 2010b; Smith and others 2006). The observation that treatment with LRRK2 kinase inhibitors can rescue cell toxicity induced by pathogenic LRRK2 in cell culture (Cooper and others 2012; Lee and others 2010a; Sheng and others 2012; Yao and others 2013) and in rodent brain (Daher and others 2015; Lee and others 2010a) has made LRRK2 kinase activity one of the most prevailing disease-modifying targets. The finding that LRRK2 kinase inhibition can also protect against $\alpha$-synuclein-induced toxicity in rodent brain (Daher and others 2015) even suggests that LRRK2 kinase activity could be a valid target for PD patients without LRRK2 mutations. Consequently, many companies have sought to develop potent and selective LRRK2 kinase inhibitors (overview of patents in Deng and others 2012; Kethiri and Bakthavatchalam 2014). Although beneficial effects of LRRK2 kinase inhibition have been reported in independent studies, some caution is warranted as we might not yet fully comprehend all consequences of LRRK2 kinase inhibitor treatment.

\section{The Complex Regulation of LRRK2 (De)Phosphorylation}

\section{LRRK2 Phosphorylation: One Term, Different Concepts}

LRRK2 contains many serine and threonine residues, of which several are found to be phosphorylated (Gloeckner and others 2010; Lobbestael and others 2012; Reyniers and others 2014). In general, these sites can be subdivided into two groups: autophosphorylation sites (Fig. 1, in green), which are identified as being phosphorylated by the LRRK2 kinase itself, and sites that are considered to be phosphorylated by kinases other than LRRK2, which we will refer to as constitutive phosphorylation sites (Fig. 1, in dark blue).

Autophosphorylation sites were identified in in vitro assays and although they are found within the different domains of LRRK2, many of them cluster in or around the central ROC domain. LRRK2 is suggested to prefer threonine residues as autophosphorylation sites (Nichols and others 2009; Pungaliya and others 2010). However, up till now only two threonine residues, T1410, (Gloeckner and others 2010; Pungaliya and others 2010) and T1503 (Lavalley and others 2016; Moehle and others 2012; Webber and others 2011) and one serine residue, S1292, (Gloeckner and others 2010; Sheng and others 2012) have been confirmed in a cellular context (Lavalley and others 2016; Moehle and others 2012; Pungaliya and others 2010; Reynolds and others 2014; Sheng and others 2012) or in vivo (Sheng and others 2012) (Fig. 1, in green).

The serines of the constitutive phosphorylation sites are highly conserved (Nichols and others 2010) and most of them cluster between the ANK- and the LRR-domain. Different findings support the idea that these sites are phosphorylated by kinases other than LRRK2 (Dzamko and others 2010). First, when LRRK2 is dephosphorylated at residues S910 and S935 by LRRK2 kinase inhibition, immunoprecipitated and washed to remove the inhibitor, no increase in phosphorylation at these sites can be observed after addition of LRRK2 protein and ATP (Nichols and others 2010). Second, the lack of correlation between kinase activity and the phosphorylation status of the constitutive sites (Ito and others 2014; Reynolds and others 2014) supports the role of cellular upstream kinases other than LRRK2. LRRK2 mutations, G2019S and K1906M, display either increased or strongly reduced kinase activity compared with wild-type (WT) LRRK2, respectively, but have phosphorylation levels at S935 comparable to WT LRRK2 (Lobbestael and others 2013; Nichols and others 2010). Third, different kinase-dead mutants have different effects on constitutive phosphorylation levels as both reduced or similar levels of S935 phosphorylation compared to WT LRRK2 were observed (Ito and others 2014). Finally, several pathogenic mutants (R1441C/G/H, Y1699C, and I2020T) display decreased constitutive phosphorylation at S935 (Nichols and others 2010), despite their increased autophosphorylation at S1292, which indicates increased LRRK2 kinase activity.

Constitutive phosphorylation sites are rapidly dephosphorylated after exposure to LRRK2 kinase inhibitors ( $>80 \%$ dephosphorylation after 90 minutes; Deng and others 2011). We previously showed that there is a strong 


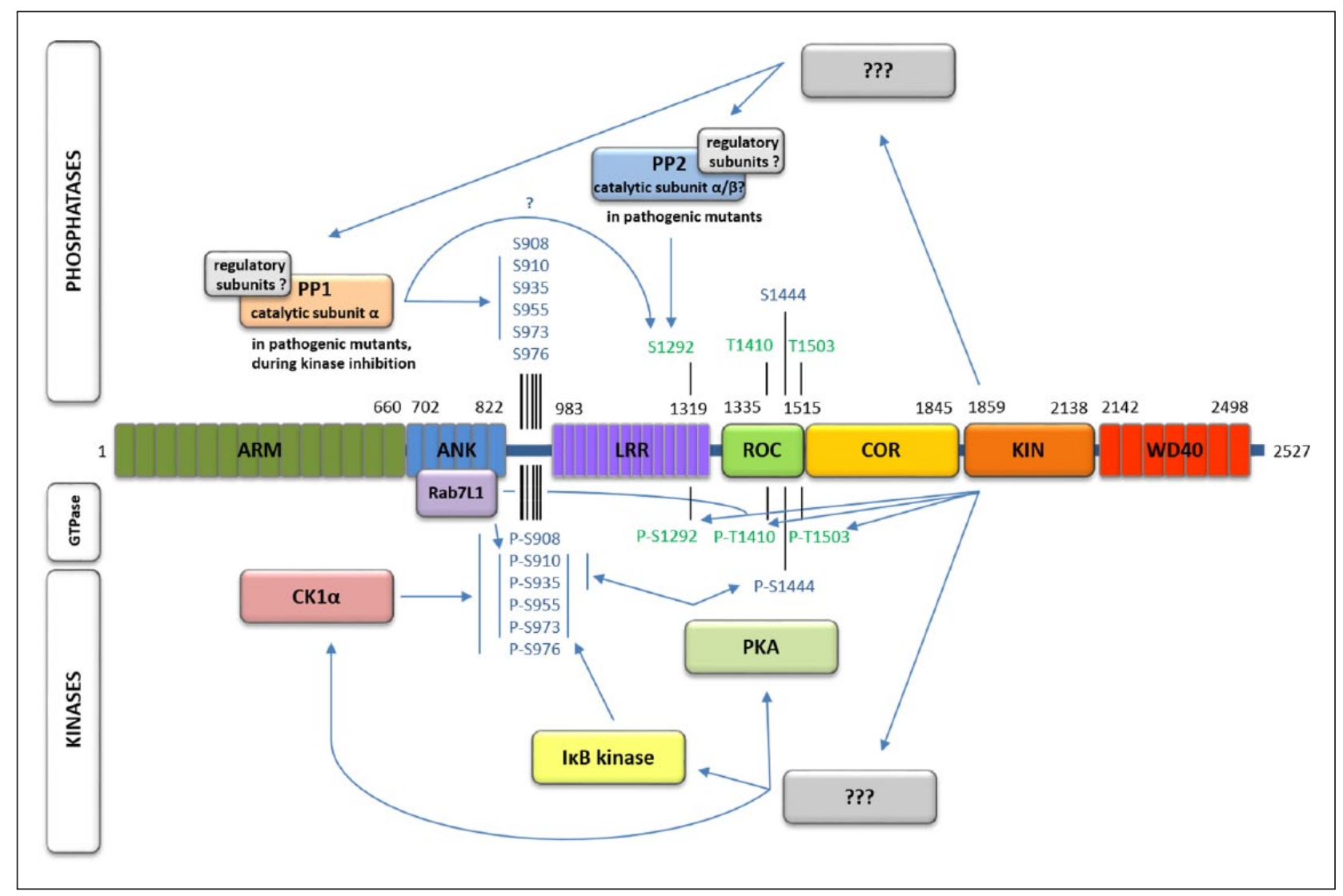

Figure 2. Schematic representation of reported regulators of leucine-rich repeat kinase 2 (LRRK2) phosphorylation sites.

correlation between the efficacy of compounds to inhibit in vitro LRRK2 kinase activity and their ability to dephosphorylate LRRK2 in cells (Vancraenenbroeck and others 2014). This observation, together with the fact that detection of phosphorylated autophosphorylation sites in cells is significantly weaker than detection of phosphorylated S935, resulted in the use of dephosphorylated S935 as an indirect readout for LRRK2 kinase inhibitor activity (Delbroek and others 2013; Dzamko and others 2010; Vancraenenbroeck and others 2014). The inhibition of LRRK2 kinase activity thus induces both decreased phosphorylation levels at S1292 (directly) and at the constitutive sites (indirectly). Intriguingly, dephosphorylated constitutive phosphorylation sites are also found in the most of pathogenic mutations, as well as in different brain regions, including the $\mathrm{SNpc}$ of idiopathic PD patients (Dzamko and others 2017). The finding that a potential protective agent induces the same protein phosphatase 1 (PP1)-mediated LRRK2 dephosphorylation as seen in pathogenic mutants (Lobbestael and others 2013) (see next paragraph) is a fascinating observation in light of the therapeutic use of LRRK2 kinase inhibitors and might indicate that LRRK2 dephosphorylation at the constitutive sites is not a pathogenic mechanism.

\section{Upstream Regulators of LRRK2 Phosphorylation}

Identification of upstream kinases, phosphatases, or other regulatory proteins of LRRK2 phosphorylation sites will be crucial to understand how LRRK2 can influence its phosphorylation status, directly or indirectly (Fig. 2). Casein kinase $1 \alpha(\mathrm{CK} 1 \alpha)$ was identified as an upstream kinase of LRRK2 at S908, S910, S935, S955, S973, and S976 in cell culture as well as ex vivo in striatum (Chia and others 2014). Interestingly, the interaction between LRRK2 and CK1 $\alpha$ is diminished upon LRRK2-IN1 treatment of WT LRRK2, but not of the kinase-dead variant K1906M (Chia and others 2014). This finding suggests a role for LRRK2 kinase activity in CK1 $\alpha$ recruitment or for the constitutive phosphorylation status given that K1906M LRRK2 does not dephosphorylate (at least at S910 and S935) upon kinase inhibition (Ito and others 2014; Lobbestael and others 2016). Other upstream regulators of LRRK2 phosphorylation include inhibitor of nuclear factor $\kappa B$ kinase subunits $\alpha$ and $\beta$ (IKK $\alpha$ and $\beta$ ) and the IKKrelated kinases (Dzamko and others 2012). These regulators were shown to phosphorylate LRRK2 S910 and S935 in bone marrow-derived macrophages upon 
stimulation of the toll-like receptor (TLR) pathway (Dzamko and others 2012). A role for IKK-kinases in the regulation of LRRK2 S935 phosphorylation was also observed in the neuronal SH-SY5Y cell line and in HEK293 cells for LRRK2 S910, S935, S955 and S973 (Hermanson and others 2012). A third upstream kinase that has been suggested in different independent studies is protein kinase A (PKA) (reviewed in Greggio and others 2017). Initial evidence was provided a decade ago, when Ito and colleagues showed decreased metabolic labeling of overexpressed LRRK2 after treating HEK293 cells with different PKA inhibitors (Ito and others 2007). However, PKA-mediated LRRK2 phosphorylation was only confirmed many years later by two research groups after S910 and S935 phosphospecific antibodies became available ( $\mathrm{Li}$ and others 2011; Muda and others 2014). The specific link with LRRK2 is however still unresolved since other studies were not able to confirm PKA as an upstream kinase of LRRK2. Indeed, a significant decrease of phosphorylation at S910, S935, S955, and S973 sites was described in conditions of PKA activation (Reynolds and others 2014) in HEK293 cells and no effect of PKA inhibition or activation was observed on the phosphorylation status of S935 (Hermanson and others 2012). In addition to these well-characterized LRRK2 constitutive phosphorylation sites, S1444 was identified as a PKA phosphorylation site. This PKA recognition site encloses the pathogenic hotspot R1441 and is not recognized when the arginine is mutated, leading to reduced phosphorylation at S1444, reduced 14-3-3 binding (which we will further discuss in a following section) and increased kinase activity (Muda and others 2014). It should be noted that this observation awaits confirmation and might be cell type specific as another study reported that forskolininduced activation of PKA was not able to affect S1292 autophosphorylation, a measure for LRRK2 kinase activity (Reynolds and others 2014). Altogether, PKA appears to be part of the regulatory complex of LRRK2 phosphorylation, albeit unresolved whether this is a direct effect and dependent on specific experimental conditions. The conflicting reports, together with the accumulating evidence for a functional interaction between the two kinases in different cell types (Greggio and others 2017), suggests that a PKA-dependent regulation of LRRK2 phosphorylation results from a much more complex functional interaction in different cellular pathways. Indications that individual phosphorylation sites are regulated by different proteins comes from experiments using the LRRK2 A2016T variant, which shows a strongly reduced ability to bind inhibitors. LRRK2 kinase inhibitor treatment of this LRRK2 variant induces dephosphorylation at S955, but not at S910 and S935. This could imply that the kinase responsible for S955 phosphorylation is non-specifically inhibited, leading to the observed dephosphorylation at
S955, but not at S910/S935 (Ito and others 2014). Finally, besides the ones discussed above, several other potential kinases have been proposed to regulate LRRK2, but still await confirmation (summarized in Lobbestael and others 2012).

Rab7L1 (also known as Rab29) is one of the Rab GTPase proteins that have been proposed as LRRK2 substrates (Steger and others 2016; Steger and others 2017) and is known as a functional interaction partner of LRRK2 (Beilina and others 2014; Dodson and others 2012; Fujimoto and others 2018; Kuwahara and others 2016; MacLeod and others 2013; Pihlstrøm and others 2015; Steger and others 2016). This interaction is of particular interest given that Rab7L1 is a candidate gene located in the PD risk-associated locus PARK16 (Satake and others 2009). Only very recently, Rab7L1 was found to be a major regulator of LRRK2 kinase activity and its phosphorylation (Liu and others 2018; Purlyte and others 2018). Rab7L1 induces recruitment of LRRK2 to the trans-Golgi network, where its kinase activity is stimulated, resulting in increased S1292 phosphorylation. This process appears to depend on LRRK2 GTP-binding capacity as the presence of pathogenic mutations R1441C/G and Y1699C further enhance this recruitment and subsequent S1292 phosphorylation, in contrast to the GTP binding dead mutant T1348N, which completely inhibits S1292 autophosphorylation. In addition, phosphorylation at the constitutive phosphorylation sites S910, S935, S955, and S973 also depends on Rab7L1 activity as reduced phosphorylation at these sites is observed in conditions of decreased Rab7L1 interaction or in Rab7L1 knock-out cell lines (Purlyte and others 2018).

When it comes to phosphatases, only protein phosphatase $1 \alpha(\mathrm{PP} 1 \alpha)$ is identified to affect the constitutive phosphorylation sites so far. We and others showed previously that increased recruitment of PP $1 \alpha$ underlies the dephosphorylation at S910, S935, S955, and S973 induced by LRRK2 kinase inhibition, the pathogenic mutation R1441G and most likely also the other dephosphorylated pathogenic mutants (Lobbestael and others 2013; Mamais and others 2014; Zhao and others 2015). In contrast, phosphatases involved in the regulation of the LRRK2 autophosphorylation sites remain ambiguous and interpretation of the regulation at S1292 is complicated by the fact that kinase inhibitor treatment also reduces the direct phosphorylation at this site, in contrast to S910, S935, S955, and S973, which are not directly phosphorylated by LRRK2. LRRK2 kinase inhibitor-induced reduction of phosphorylated $\mathrm{S} 1292$ cannot be prevented by exposure to calyculin A (CalA, an inhibitor of PP1 and protein phosphatase 2A), or to okadaic acid (OA, an inhibitor of PP2A) (Reynolds and others 2014). Still, PP1 and/or PP2A are most likely involved in the basal regulation of S1292 phosphorylation, at least in the G2019S and R1441G 
variants, given the upregulated S1292 phosphorylation upon OA or CalA treatment (Reynolds and others 2014). In addition, PP2A was suggested to play a role in LRRK2 dysfunction as LRRK2 R1441C or G2019S-induced toxicity could be aggravated or reduced by PP2A knockdown or activation, respectively (Athanasopoulos and others 2016). Whether this is related to a direct regulation of the LRRK2 phosphorylation status is unclear.

The LRRK2 phosphorylation balance appears to be a regulating element of several cellular functions including its interaction with 14-3-3 proteins, its cellular distribution and its role during an immune response (see next paragraphs). Identification of the regulators of this balance will therefore be crucial to understand how LRRK2 is (de)regulated to execute its (dys)function and thus to interfere with pathogenic processes.

\section{Biological Effects Related to LRRK2 (De)Phosphorylation}

\section{Interaction with 14-3-3 Proteins}

14-3-3 proteins are among the best described protein interactors of LRRK2. The LRRK2-14-3-3 relationship is particularly exciting since 14-3-3 proteins are highly expressed in the brain, play a key role in cell survival (Porter and others 2006) and have already been implicated in several neurological disorders, including PD (Berg and others 2003; Chen and others 2003; Ostrerova and others 1999; Plotegher and others 2014; Sato and others 2006; Ubl and others 2002; Yacoubian and others 2010). 14-3-3 protein dimers are known to interact with LRRK2 in a phospho-dependent manner (Dzamko and others 2010; Muda and others 2014; Reyniers and others 2014; Nichols and others 2010). However, how this interaction exactly occurs is not completely resolved. A 14-3-3 dimer was suggested to bind to LRRK2 at both P-S910 and P-S935 (Nichols and others 2010). Yet, another study only found binding of 14-3-3 to phosphorylated S910, in addition to a much higher affinity interaction at P-S1444 (Muda and others 2014) (Fig. 3). The fact that also LRRK2 exists as a dimer further complicates the interpretation since 14-3-3 dimer interactions might occur at phosphorylated residues of two different LRRK2 molecules. 14-3-3 proteins can protect interaction partners from dephosphorylation (Hausser and others 2006), which might also be the case for LRRK2. Alanine substitutions at positions S910 or S935 strongly reduce phosphorylation at S935 and S910 respectively (Nichols and others 2010), while alanine mutations at S955 or S973 do not affect S910 or S935 phosphorylation (Doggett and others 2012). We can therefore hypothesize that a 14-3-3 dimer binds P-S910/P-S935, and that loss of one of the phosphorylated binding sites abolishes this interaction. With 14-3-3 unable to bind, the remaining phosphorylated serine would be left exposed to phosphatases for subsequent dephosphorylation. Indeed, every condition that leads to dephosphorylation of at least one of the constitutive phosphorylation sites S910, S935 or S1444 results in a loss or strongly reduced interaction with 14-3-3 proteins. A similar reduced 14-3-3 binding is observed for most of the pathogenic mutants $(\mathrm{N} 1437 \mathrm{H}$, $\mathrm{R} 1441 \mathrm{C} / \mathrm{G} / \mathrm{H}, \mathrm{Y} 1699 \mathrm{C}$ and $\mathrm{I} 2020 \mathrm{~T})$ and the risk factor G2385R (Chia and others 2014; Lobbestael and others 2013; Nichols and others 2010). Also, inhibition of LRRK2 kinase activity (Chia and others 2014; Deng and others 2011; Doggett and others 2012; Dzamko and others 2010; Li and others 2011; Lobbestael and others 2013) or of the upstream kinase CK1 $\alpha$ (Chia and others 2014) leads to weakened 14-3-3 interaction. The cellular consequences of reduced LRRK2-14-3-3 binding are not completely understood. 14-3-3 binding is proposed to play a role in the release of LRRK2 in urinary exosomes (Fraser and others 2013) and is related to LRRK2 distribution and protein ubiquitination in the cell (Zhao and others 2015). Interestingly, binding of 14-3-3 proteins to LRRK2 S910 and S1444 was shown to decrease kinase activity in vitro (Muda and others 2014). This is in line with the observation that overexpression of 14-3-30 proteins can decrease LRRK2 G2019S kinase activity and rescue the reduced neurite length of primary neurons overexpressing LRRK2 G2019S or R1441G (Lavalley and others 2016). These findings suggest a protective role for 14-3-30 proteins in LRRK2-related toxicity. However, a more complex relation with 14-3-3 proteins might be in place since LRRK2 kinase inhibition exerts its protective effects while disrupting the 14-3-3 binding (Lavalley and others 2016).

\section{Cellular Localization}

LRRK2 displays a homogenous cellular distribution under basal conditions (Alegre-Abarrategui and others 2009; Nichols and others 2010). It associates with membrane structures as a functional dimer, most likely through intermolecular interaction of the ROC-COR domains (Berger and others 2010; Deng and others 2008; Greggio and others 2008; Jorgensen and others 2009). In the presence of several disease-associated LRRK2 mutations (AlegreAbarrategui and others 2009; Dzamko and others 2010; Kett and others 2012; Lobbestael and others 2013; Nichols and others 2010; Skibinski and others 2014) or after pharmacological LRRK2 kinase inhibition (Deng and others 2011; Dzamko and others 2010; Reyniers and others 2014; Rudenko and others 2012), LRRK2 can be found in intracellular inclusions, often described as filamentous, skeinlike structures. These structures are associated with microtubules (Dzamko and others 2010; Kett and others 2012) and were described by Alegre-Abarrategui and colleagues as "membrane-surrounded elongated structures 


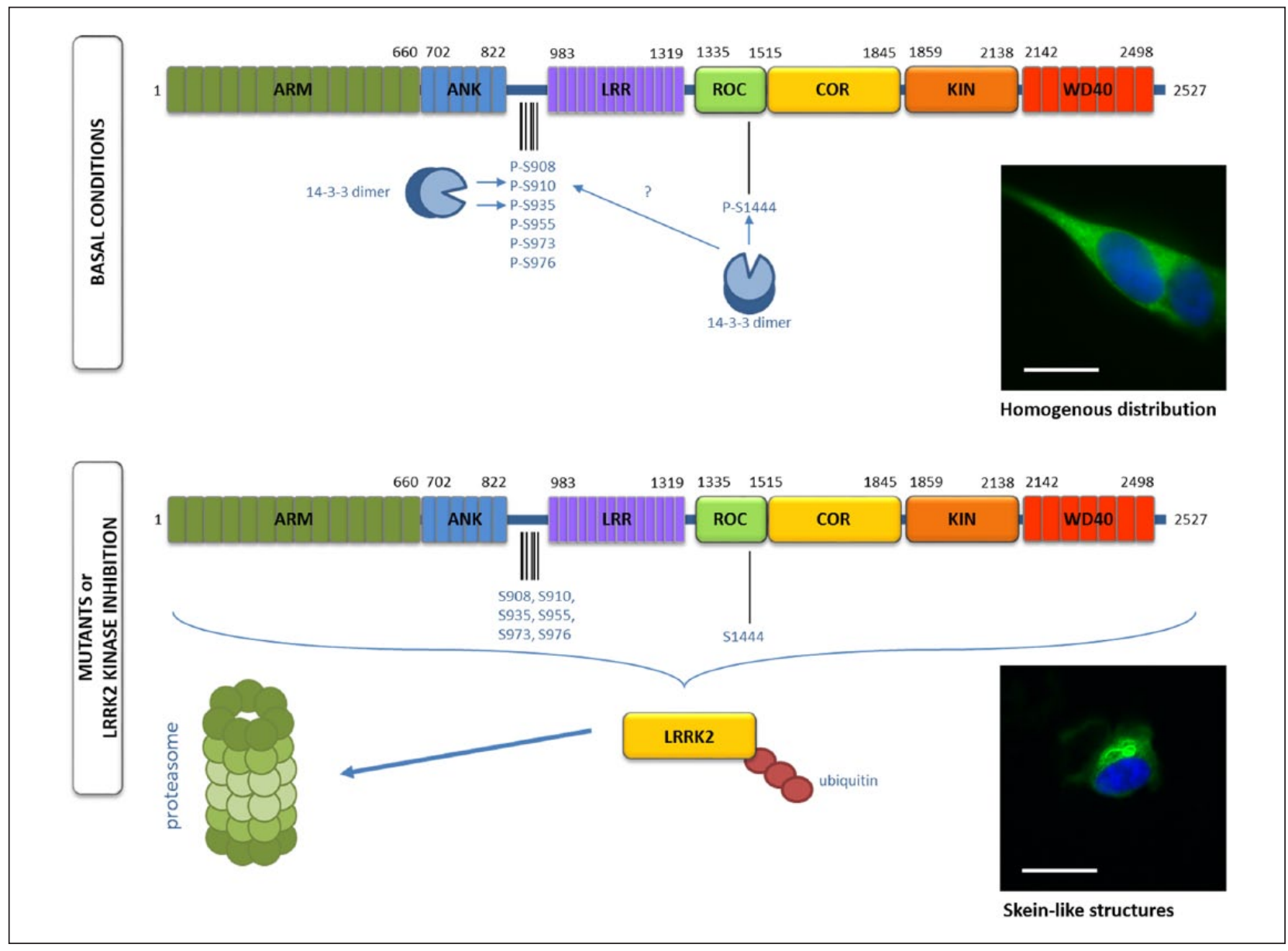

Figure 3. Molecular changes observed upon I4-3-3 binding to leucine-rich repeat kinase 2 (LRRK2). Scale bars represent I5 $\mu$ m.

composed of a fine granular material enclosing a densely packed core positive for LRRK2" (Alegre-Abarrategui and others 2009). LRRK2 phosphorylation is most likely one of the determining factors in the formation of these structures, since they are linked to conditions of decreased phosphorylation at S910/S935 and thus abrogated 14-3-3 interaction. Moreover, we showed that inhibition of phosphatases PP1 and PP2A can prevent LRRK2 to relocalize in pathogenic conditions (Lobbestael and others 2013). Still, additional factors are probably involved since the LRRK2 G2385R risk factor displays impaired 14-3-3 binding and S910/S935 phosphorylation (Nichols and others 2010; Rudenko and others 2012), but does not accumulate in skein-like structures (Rudenko and others 2012). Strikingly, abolishing kinase activity of dephosphorylated pathogenic mutants by introducing the kinasedead K1906R mutation induced a homogenous distribution of these mutants as seen in WT LRRK2 (Kett and others 2012). This is in line with the observation that the G2385R mutant displays reduced kinase activity compared with WT LRRK2 (Rudenko and others 2012). The observation that both pharmacological LRRK2 kinase inhibition and pathogenic mutants with increased kinase activity result in LRRK2 relocalization (Alegre-Abarrategui and others 2009; Deng and others 2011; Dzamko and others 2010; Greggio and others 2006; Kett and others 2012; Lobbestael and others 2013; Reyniers and others 2014; Rudenko and others 2012; Smith and others 2005) (Fig. 3) raises questions whether LRRK2 kinase activity is involved in the regulation of LRRK2 distribution and to what extent these filamentous structures are comparable in condition of inhibition and pathogenic mutations. Recently, it has been suggested that the GTP-binding capacity of LRRK2 is the main determinant of LRRK2 relocalization. Indeed, non-hydrolyzable GTP strongly induced the formation of filamentous structures, while treatment with LRRK2-GTP-binding inhibitors or the presence of mutations that disrupt GTP-binding prevented relocalization (Blanca Ramírez and others 2017b). Although the skein-like structures are a remarkable phenomenon, it should be pointed out that their physiological relevance is still under debate given that skein-like structures have only been reported in conditions of LRRK2 overexpression so far. 


\section{LRRK2 Kinase Inhibition and Destabilization}

We and others have shown that sustained LRRK2 kinase inhibition can result in reduced LRRK2 protein levels (Fell and others 2015; Fuji and others 2015; Herzig and others 2011; Lobbestael and others 2016; Skibinski and others 2014; Zhao and others 2015). This phenomenon has long been undetected given the fast kinetics of LRRK2 kinase inhibition on dephosphorylation of both constitutive and autophosphorylation sites (Daher and others 2015; Deng and others 2011; Dzamko and others 2010; Henderson and others 2015; Vancraenenbroeck and others 2014). Consequently most studies applied shortterm kinase inhibitor treatment and thus did not report inhibitor-induced LRRK2 protein loss. An exception is the reduction of a $\sim 170 \mathrm{kDa}$ truncated, but not full length, form of LRRK2, in neutrophils treated with MLi-2 for 30 minutes. The observation that treatment with high doses of PF-06447475 did not affect truncated LRRK2 protein levels (Fan and others 2018), might point to effects of MLi-2 on other proteins (e.g., cell type-specific proteases), rather than LRRK2-specific effects. Nevertheless, the differential regulation of this truncated form of LRRK2 is intriguing as we have shown a reduction of full length, but not $\sim 170 \mathrm{kDa}$ truncated, LRRK2 in the kidney of mice treated with MLi-2 for 2 days (Lobbestael and others 2016). More insight in the exact sequence, distribution, regulation, and specific function of this truncated protein will be of major interest to understand the (peripheral) function of LRRK2.

Reduced LRRK2 protein levels have also been reported in vivo in transgenic knock-in mice expressing a kinase-dead variant, pointing to LRRK2 kinase activity as a potential regulator of LRRK2 protein homeostasis (Herzig and others 2011). In line with this, functional mutants with reduced Rab7L1 interaction, and consequently reduced kinase activity and constitutive phosphorylation, display reduced protein stability (Purlyte and others 2018). Still, LRRK2 levels in brain or kidney of Rab7L1 knock-out mice are not reduced (Kuwahara and others 2016). Therefore, it would be interesting to assess LRRK2 kinase activity and phosphorylation in these mice.

A more detailed study, using S910/S935 phosphodead mutants and difopein, which induces LRRK2 dephosphorylation by inhibiting 14-3-3 protein interaction, identified S935 dephosphorylation as a mediator of LRRK2 ubiquitination and subsequent proteasomal degradation (Zhao and others 2015). However, our recent observations that S910A or S935A LRRK2 variants are degraded upon LRRK2 kinase inhibition, to the same extent as their WT counterpart, add another layer of complexity. These data suggest that dephosphorylation at one of these sites is not a critical factor in inhibitor-induced destabilization (Lobbestael and others 2016) (Fig. 3). In addition, cell-type specific mechanisms might be important for LRRK2 stability since destabilization is not observed in all cell types after LRRK2 kinase inhibitor treatment (e.g., mouse primary astrocytes) (Lobbestael and others 2016)). The observation that LRRK2 is destabilized or degraded after LRRK2 kinase inhibition has important implications for the development of LRRK2 kinase inhibitors as a PD drug. On the one hand, preclinical toxicity studies using distinct LRRK2 kinase inhibitors have revealed morphological changes in type II pneumocytes of the lung, in rodents (Fell and others 2015) and non-human primates (Fuji and others 2015). These observations are reminiscent of changes seen in the lung of LRRK2 knock-out mice (Baptista and others 2013). This suggests a direct correlation between decreased LRRK2 protein levels and LRRK2 kinase inhibition. However, not all treated non-human primates with a lung phenotype showed reduced LRRK2 levels in the lung (Fuji and others 2015). Besides possible cell-type specific effects, it is currently unclear why LRRK2 kinase inhibitors induce dephosphorylation in different organs and different species, but do not always induce destabilization (Daher and others 2015; Fell and others 2015; Fuji and others 2015; Lobbestael and others 2016; Zhao and others 2015). Although initial studies suggest that the lung phenotype is reversible and without serious functional implications, it is an important feature of LRRK2 kinase inhibition to take into account during clinical development. It is worth mentioning that preclinical safety studies that showed a lung phenotype, have assessed the effect of LRRK2 kinase inhibitor treatment on lungs with normal WT LRRK2 kinase activity (Fell and others 2015; Fuji and others 2015). These observations leave open the possibility that reducing the elevated kinase activity to basal WT levels in a pathogenic condition, rather than eliminating all kinase activity can prevent potential peripheral side effects. Interestingly, heterozygous LRRK2 knock-out mice do not display morphological lung changes (Herzig and others 2011), suggesting that a more modest reduction of kinase activity can by-pass the observed lung phenotype. However, it is still unclear, how such a restricted kinase inhibition could be obtained and how it would impact the potential neuroprotective effects. In addition, identification of the determinants of LRRK2 destabilization could provide crucial information to prevent potential side effects of LRRK2 inhibition. On the other hand, inhibitor-induced destabilization might entail a new therapeutic strategy, as it has been suggested that the beneficial effects of LRRK2 kinase inhibition can be attributed to reduced LRRK2 protein levels, rather than a reduction of its kinase activity per se (Skibinski and others 2014). However, protective effects exerted by LRRK2 kinase inhibitors cannot 
merely be attributed to a reduction in proteins levels since no LRRK2 destabilization was observed in a viral vectorbased $\alpha$-synuclein rat model that was protected from neurodegeneration by LRRK2 kinase inhibitor treatment (Daher and others 2015). Still, with regard to drug development, the idea of reducing total LRRK2 protein levels is interesting and recently supported by the finding that LRRK2 antisense oligonucleotides can reduce the formation of $\alpha$-synuclein inclusions in a PD mouse model (Zhao and others 2017).

In addition to inhibitor-induced destabilization, the regulators of LRRK2 protein homeostasis in basal conditions also have to be identified. To date, only few studies have reported on the putative effect of pathogenic mutations on LRRK2 protein stability. Interestingly, the dephosphorylated LRRK2 variants I2020T (Ohta and others 2009), R1441C (Greene and others 2014) and G2385R (Rudenko and others 2017) are suggested to display increased degradation rates compared with WT LRRK2, which is in line with the observation that pathogenic mutations with reduced S935 phosphorylation display increased ubiquitination (Zhao and others 2015). In contrast, the G2019S mutant was reported to have an increased protein half-life (Orenstein and others 2013), although this was not observed by others (Wang and others 2008).

Finally, when assessing LRRK2 protein stability, the choice of protease inhibitor (Fan and others 2018) or lysis buffer composition (own unpublished observations) should be well-considered given possible effects on LRRK2 protein degradation.

\section{Regulation of LRRK2 \\ Phosphorylation and Expression Levels in Immune Cells}

Multiple evidence suggests that disturbed and elevated peripheral and central immune responses contribute to the pathogenesis of PD (Su and Federoff 2014). Elevated tumor necrosis factor- $\alpha$ (TNF- $\alpha$ ) and interferon- $\gamma$ (IFN$\gamma$ ) levels were found in the CSF and in postmortem brain tissue of PD patients (Mogi and others 1994; Mogi and others 1996). Very recent studies showed that both monocytes and T-cells from PD patients produce an increased amount of pro-inflammatory cytokines after stimulation with IFN- $\gamma$ (Cook and others 2017) or $\alpha$-synuclein peptides and fibrils (Sulzer and others 2017). High LRRK2 protein levels are found in different types of immune cells, including monocytes, neutrophils, and B-cells (Fan and others 2018; Gardet and others 2010; Hakimi and others 2011; Kubo and others 2010; Thévenet and others 2011) and microglia in the central nervous system (Gillardon and others 2012; Moehle and others 2012). Interestingly, PD patients were shown to have increased
LRRK2 protein levels in different types of monocytes (Bliederhaeuser and others 2016; Cook and others 2017), B-cells, and T-cells (Cook and others 2017), compared with healthy controls.

In the peripheral immune system, increased LRRK2 phosphorylation and total protein levels have been reported in different cell types on stimulation (Cook and others 2017; Gardet and others 2010; Hakimi and others 2011; Hongge and others 2015; Kuss and others 2014; Moehle and others 2012; Thévenet and others 2011). Stimulation of the TLR pathway in bone marrow-derived macrophages or a macrophage cell line induced increased LRRK2 phosphorylation levels at S910 and S935 (Dzamko and others 2012; Schapansky and others 2014). I $\kappa$ B kinase members were identified as upstream kinases of LRRK2 phosphorylation, but only after stimulation (Dzamko and others 2012). Under these conditions, increased LRRK2 phosphorylation could not be reversed by kinase inhibition, while treatment with LRRK2 kinase inhibitors induced LRRK2 dephosphorylation in basal conditions (Dzamko and others 2012; Schapansky and others 2014). The increase in LRRK2 phosphorylation in lipopolysaccharide (LPS)-stimulated macrophages was shown to precede LRRK2 dimerization and membrane association, representing the active state of LRRK2 (Schapansky and others 2014). The exact role of LRRK2 (phosphorylation) in LPS-induced activation in macrophages is currently unclear, but various independent studies were unable to detect changes in cytokine release under various experimental conditions including LRRK2 deficiency (Dzamko and others 2012; Hakimi and others 2011; Liu and others 2011; Wandu and others 2015) and overexpression of WT or pathogenic LRRK2 variants (Hakimi and others 2011; Moehle and others 2015), suggesting that LRRK2 is not a critical mediator in this process.

In the central nervous system, LRRK2 phosphorylation and protein levels appear to be strictly controlled in immune cells and differentially regulated during cell activation. Activation of the TLR-4 pathway by LPS results in increased LRRK2 protein levels in microglia in vivo and in primary microglia in vitro (Daher and others 2014; Gillardon and others 2012; Moehle and others 2012), although one study could not confirm this finding in BV2 cells and primary microglia (Russo and others 2015). The increase in LRRK2 protein levels in vivo were accompanied by increased LRRK2 kinase activity as shown by increased autophosphorylation after LRRK2 immunoprecipitation from LPS-injected SNpc (Moehle and others 2012). This is in line with the finding that LRRK2 in LPS-activated microglia displays increased S935 phosphorylation and subsequent dimerization and membrane association (Schapansky and others 2014), which might represent the active state of the protein, as 
described earlier in macrophages (Berger and others 2010; Greggio and others 2008; Sen and others 2009). LRRK2 is proposed to act as a positive regulator of neuroinflammation in primary microglia, since reduced LRRK2 levels or LRRK2 kinase inhibition were found to result in an attenuated inflammatory response on LPS or $\alpha$-synuclein fibril treatment (Kim and others 2012; Ma and others 2016; Moehle and others 2012; Russo and others 2015). In contrast, LPS-mediated stimulation of microglia overexpressing the R1441G pathogenic mutant, exhibit an increased cytokine expression and secretion. The finding that conditioned medium from these activated R1441G microglia, but not from WT microglia, induced a significant increase in cell death when exposed to neuronal cultures (Gillardon and others 2012) further points to a role for LRRK2 in neuroinflammation and related neurotoxicity. This was further corroborated by the finding that double transgenic A53T $\alpha$-synuclein/LRRK2 ${ }^{-/-}$mice do not display elevated astrocytosis or microgliosis in contrast to A53T $\alpha$-synuclein transgenic mice with a LRRK2 WT background (Lin and others 2009). In addition, LRRK2 deficientrats were protectedfromLPS- or $\alpha$-synuclein-induced toxicity and neuroinflammation (Daher and others 2014), while rats with a G2019S background displayed exacerbated LPS (Moehle and others 2015) and $\alpha$-synucleininduced toxicity and neuroinflammation, which could be blocked by LRRK2 kinase inhibition (Daher and others 2015). In conclusion, gaining insight in this microglianeuron interaction and in the role of LRRK2 (phosphorylation) in the (central) immune response will be indispensable to understand the processes that contribute to the pathogenesis of PD.

\section{Conclusion}

Genetic variations in LRRK2 are one of the most common known determinants of PD. As there is currently no curative treatment for PD, gaining insight into the function of LRRK2 and its role in disease pathogenesis is of major importance. LRRK2 phosphorylation appears to be tightly regulated and a major determinant of LRRK2 function in neurons as well as in immune cells. The field has moved forward significantly by identifying upstream regulators of LRRK2 (de)phosphorylation, by investigating the molecular and cellular consequences of LRRK2 (de)phosphorylation and by studying the role and regulation of LRRK2 (phosphorylation) in conditions of immune cell stimulation.

Still, to date, we do not know whether constitutive LRRK2 dephosphorylation or increased LRRK2 autophosphorylation, as observed for most pathogenic mutants, is a relevant pathogenic feature. Interestingly, idiopathic PD patients are reported to display decreased
LRRK2 phosphorylation at S910, S935 and S973 in different brain regions, including the SN (Dzamko and others 2017) but increased phosphorylation at S1292 in urinary exosomes (Fraser and others 2016a; Fraser and others 2016b). In addition, it is still not clear how this constitutive dephosphorylation seen in pathogenic conditions, relates to the dephosphorylation induced by LRRK2 kinase inhibition. Increasing our knowledge on the regulation of basal LRRK2 phosphorylation and on the functional implications of a disturbed LRRK2 phosphorylation balance may therefore be significantly speed up our search for biomarkers, new therapeutic PD targets and the development of LRRK2 kinase inhibitors.

\section{Acknowledgments}

We thank Sarah Libbrecht, Wouter Peelaerts, and Veronique Daniëls for critical reading.

\section{Declaration of Conflicting Interests}

The author(s) declared no potential conflicts of interest with respect to the research, authorship, and/or publication of this article.

\section{Funding}

The author(s) disclosed receipt of the following financial support for the research, authorship, and/or publication of this article: Financial support from the Michael J. Fox Foundation, KU Leuven, Flanders Innovation \& Entrepreneurship (VLAIO) (doctoral fellowship TDW) and Research Foundation Flanders (FWO, projects G0E1917N and SBOS006617N) is gratefully acknowledged.

\section{References}

Alegre-Abarrategui J, Christian H, Lufino MMP, Mutihac R, Venda LL, Ansorge O, and others. 2009. LRRK2 regulates autophagic activity and localizes to specific membrane microdomains in a novel human genomic reporter cellular model. Hum Mol Genet 18:4022-34.

Athanasopoulos PS, Jacob W, Neumann S, Kutsch M, Wolters D, Tan EK, and others. 2016. Identification of protein phosphatase $2 \mathrm{~A}$ as an interacting protein of leucine-rich repeat kinase 2. Biol Chem 397:541-54.

Baptista MAS, Dave KD, Frasier MA, Sherer TB, Greeley M, Beck MJ, and others. 2013. Loss of leucine-rich repeat kinase 2 (LRRK2) in rats leads to progressive abnormal phenotypes in peripheral organs. PLoS One 8:e80705.

Beilina A, Rudenko IN, Kaganovich A, Civiero L, Chau H, Kalia SK, and others. 2014. Unbiased screen for interactors of leucine-rich repeat kinase 2 supports a common pathway for sporadic and familial Parkinson disease. Proc Natl Acad Sci U S A 111:2626-31.

Berg D, Holzmann C, Riess O. 2003. 14-3-3 proteins in the nervous system. Nat Rev Neurosci 4:752-62.

Berger Z, Smith KA, Lavoie MJ. 2010. Membrane localization of LRRK2 is associated with increased formation of the 
highly active LRRK2 dimer and changes in its phosphorylation. Biochemistry 49:5511-23.

Beyer K, Domingo-Sàbat M, Ariza A. 2009. Molecular pathology of Lewy body diseases. Int J Mol Sci 10:724-45.

Blanca Ramírez M, Lara Ordóñez AJ, Fdez E, Hilfiker S. 2017a. LRRK2: from kinase to GTPase to microtubules and back.Biochem Soc Trans 45:141-6.

Blanca Ramírez M, Lara Ordóñez AJ, Fdez E, Madero-Pérez J, Gonnelli A, Drouyer M, and others. 2017b. GTP binding regulates cellular localization of Parkinson's diseaseassociated LRRK2. Hum Mol Genet 26:2747-67.

Bliederhaeuser C, Zondler L, Grozdanov V, Ruf WP, Brenner D, Melrose HL, and others. 2016. LRRK2 contributes to monocyte dysregulation in Parkinson's disease. Acta Neuropathol. Commun 4:123.

Chang D, Nalls MA, Hallgrímsdóttir IB, Hunkapiller J, van der Brug M, Cai F, and others. 2017. A meta-analysis of genome-wide association studies identifies 17 new Parkinson's disease risk loci. Nat Genet 49:1511-6.

Chen H-K, Fernandez-Funez P, Acevedo SF, Lam YC, Kaytor MD, Fernandez MH, and others. 2003. Interaction of Aktphosphorylated Ataxin-1 with 14-3-3 mediates neurodegeneration in spinocerebellar ataxia type 1. Cell 113:457-68.

Chia R, Haddock S, Beilina A, Rudenko IN, Mamais A, Kaganovich A, and others. 2014. Phosphorylation of LRRK2 by casein kinase $1 \alpha$ regulates trans-Golgi clustering via differential interaction with ARHGEF7. Nat Commun 5:5827.

Clark LN, Nicolai A, Afridi S, Harris J, Mejia-Santana H, Strug L, and others. 2005. Pilot association study of the $\beta$-glucocerebrosidase N370S allele and Parkinson's disease in subjects of Jewish ethnicity. Mov Disord 20:100-3.

Connolly BS, Lang AE. 2014. Pharmacological treatment of Parkinson disease - a review. JAMA 311:1670-83.

Cook DA, Kannarkat GT, Cintron AF, Butkovich LM, Fraser $\mathrm{KB}$, Chang J, and others. 2017. LRRK2 levels in immune cells are increased in Parkinson's disease. NPJ Parkinsons Dis $3: 11$.

Cooper O, Seo H, Andrabi S, Guardia-Laguarta C, Graziotto J, Sundberg M, and others. 2012. Pharmacological rescue of mitochondrial deficits in iPSC-derived neural cells from patients with familial Parkinson's disease. Sci Transl Med 4:141ra90.

Daher JPL, Abdelmotilib HA, Hu X, Volpicelli-Daley LA, Moehle MS, Fraser KB, and others. 2015. Leucine-rich repeat kinase 2 (LRRK2) pharmacological inhibition abates $\alpha$-synuclein gene-induced neurodegeneration. J Biol Chem 290:19433-44.

Daher JPL, Volpicelli-Daley LA, Blackburn JP, Moehle MS, West AB. 2014. Abrogation of $\alpha$-synuclein-mediated dopaminergic neurodegeneration in LRRK2-deficient rats. Proc Natl Acad Sci U S A 111:9289-94.

Delbroek L, Van Kolen K, Steegmans L, da Cunha R, Mandemakers W, Daneels G, and others. 2013. Development of an enzyme-linked immunosorbent assay for detection of cellular and in vivo LRRK2 S935 phosphorylation. J Pharm Biomed Anal 76:49-58.

Deng J, Lewis PA, Greggio E, Sluch E, Beilina A, Cookson MR. 2008. Structure of the ROC domain from the Parkinson's disease-associated leucine-rich repeat kinase 2 reveals a dimeric GTPase. Proc Natl Acad Sci U S A 105:1499-504.

Deng X, Choi HG, Buhrlage SJ, Gray NS. 2012. Leucine-rich repeat kinase 2 inhibitors: a patent review (2006-2011). Expert Opin Ther Pat 22:1415-26.

Deng X, Dzamko N, Prescott A, Davies P, Liu Q, Yang Q, and others. 2011. Characterization of a selective inhibitor of the Parkinson's disease kinase LRRK2. Nat Chem Biol 7:203-5.

Di Fonzo A, Rohé CF, Ferreira J, Chien HF, Vacca L, Stocchi $\mathrm{F}$, and others. 2005. A frequent LRRK2 gene mutation associated with autosomal dominant Parkinson's disease. Lancet 365:412-5.

Dihanich S, Manzoni C. 2011. LRRK2: a problem lurking in vesicle trafficking? J Neurosci 31:9787-8.

Dodson MW, Zhang T, Jiang C, Chen S, Guo M. 2012. Roles of the Drosophila LRRK2 homolog in Rab7-dependent lysosomal positioning. Hum Mol Genet 21:1350-63.

Doggett EA, Zhao J, Mork CN, Hu D, Nichols RJ. 2012. Phosphorylation of LRRK2 serines 955 and 973 is disrupted by Parkinson's disease mutations and LRRK2 pharmacological inhibition. J Neurochem 120:37-45.

Dorval V, Hébert SS. 2012. LRRK2 in transcription and translation regulation: relevance for Parkinson's disease. Front Neurol 3:12.

Dzamko N, Deak M, Hentati F, Reith AD, Prescott AR, Alessi DR, and others. 2010. Inhibition of LRRK2 kinase activity leads to dephosphorylation of $\operatorname{Ser}(910) / \operatorname{Ser}(935)$, disruption of 14-3-3 binding and altered cytoplasmic localization. Biochem J 430:405-13.

Dzamko N, Gysbers AM, Bandopadhyay R, Bolliger MF, Uchino A, Zhao Y, and others. 2017. LRRK2 levels and phosphorylation in Parkinson's disease brain and cases with restricted Lewy bodies. Mov Disord 32:423-32.

Dzamko N, Inesta-Vaquera F, Zhang J, Xie C, Cai H, Arthur S, and others. 2012. The IкB kinase family phosphorylates the Parkinson's disease kinase LRRK2 at Ser935 and Ser910 during Toll-like receptor signaling. PLoS One 7:e39132.

Esteves AR, Cardoso SM. 2017. LRRK2 at the crossroad between autophagy and microtubule trafficking: insights into Parkinson's disease. Neuroscientist 23:16-26.

Fan Y, Howden AJM, Sarhan AR, Lis P, Ito G, Martinez TN, and others. 2018. Interrogating Parkinson's disease LRRK2 kinase pathway activity by assessing Rab10 phosphorylation in human neutrophils. Biochem J 475:23-44.

Farrer MJ, Stone JT, Lin C-H, Dächsel JC, Hulihan MM, Haugarvoll K, and others. 2007. Lrrk2 G2385R is an ancestral risk factor for Parkinson's disease in Asia. Parkinsonism Relat Disord 13:89-92.

Fell MJ, Mirescu C, Basu K, Cheewatrakoolpong B, DeMong DE, Ellis JM, and others. 2015. MLi-2, a potent, selective, and centrally active compound for exploring the therapeutic potential and safety of LRRK2 kinase inhibition. J Pharmacol Exp Ther 355:397-409.

Fraser KB, Moehle MS, Alcalay RN, West AB. 2016a. Urinary LRRK2 phosphorylation predicts parkinsonian phenotypes in G2019S LRRK2 carriers. Neurology 86:994-9.

Fraser KB, Moehle MS, Daher JPL, Webber PJ, Williams JY, Stewart CA, and others. 2013. LRRK2 secretion in exosomes is regulated by 14-3-3. Hum Mol Genet 22:4988-5000. 
Fraser KB, Rawlins AB, Clark RG, Alcalay RN, Standaert DG, Liu N, and others. 2016b. Ser(P)-1292 LRRK2 in urinary exosomes is elevated in idiopathic Parkinson's disease. Mov Disord 31:1543-50.

Fuji RN, Flagella M, Baca M, Baptista MAS, Brodbeck J, Chan BK, and others. 2015. Effect of selective LRRK2 kinase inhibition on nonhuman primate lung. Sci Transl Med 7:273ra15.

Fujimoto T, Kuwahara T, Eguchi T, Sakurai M, Komori T, Iwatsubo T. 2018. Parkinson's disease-associated mutant LRRK2 phosphorylates Rab7L1 and modifies trans-Golgi morphology. Biochem Biophys Res Commun 495:170815.

Gardet A, Benita Y, Li C, Sands BE, Ballester I, Stevens C, and others. 2010. LRRK2 is involved in the IFN-gamma response and host response to pathogens. J Immunol 185:5577-85.

Gillardon F, Schmid R, Draheim H. 2012. Parkinson's diseaselinked leucine-rich repeat kinase 2(R1441G) mutation increases proinflammatory cytokine release from activated primary microglial cells and resultant neurotoxicity. Neuroscience 208:41-8.

Gloeckner CJ, Boldt K, von Zweydorf F, Helm S, Wiesent L, Sarioglu H, and others. 2010. Phosphopeptide analysis reveals two discrete clusters of phosphorylation in the N-terminus and the Roc domain of the Parkinson-disease associated protein kinase LRRK2. J Proteome Res 9:1738-45.

Greene ID, Mastaglia F, Meloni BP, West KA, Chieng J, Mitchell CJ, and others. 2014. Evidence that the LRRK2 ROC domain Parkinson's disease-associated mutants A1442P and R1441C exhibit increased intracellular degradation. J Neurosci Res 92:506-16.

Greggio E, Bubacco L, Russo I. 2017. Cross-talk between LRRK2 and PKA: implication for Parkinson's disease? Biochem Soc Trans 45:261-7.

Greggio E, Cookson MR. 2009. Leucine-rich repeat kinase 2 mutations and Parkinson's disease: three questions. ASN Neuro 1:13-24.

Greggio E, Jain S, Kingsbury A, Bandopadhyay R, Lewis P, Kaganovich A, and others. 2006. Kinase activity is required for the toxic effects of mutant LRRK2/dardarin. Neurobiol Dis 23:329-41.

Greggio E, Zambrano I, Kaganovich A, Beilina A, Taymans J-M, Daniëls V, and others. 2008. The Parkinson diseaseassociated leucine-rich repeat kinase 2 (LRRK2) is a dimer that undergoes intramolecular autophosphorylation. J Biol Chem 283:16906-14.

Hakimi M, Selvanantham T, Swinton E, Padmore RF, Tong Y, Kabbach G, and others. 2011. Parkinson's disease-linked LRRK2 is expressed in circulating and tissue immune cells and upregulated following recognition of microbial structures. J Neural Transm 118:795-808.

Haugarvoll K, Rademakers R, Kachergus JM, Nuytemans K, Ross OA, Gibson JM, and others. 2008. Lrrk2 R1441C parkinsonism is clinically similar to sporadic Parkinson disease. Neurology 70:1456-60.

Haugarvoll K, Wszolek ZK. 2009. Clinical features of LRRK2 parkinsonism. Parkinsonism Relat Disord 15(Suppl. 3):S205-8.
Hausser A, Link G, Hoene M, Russo C, Selchow O, Pfizenmaier K. 2006. Phospho-specific binding of 14-3-3 proteins to phosphatidylinositol 4-kinase III $\beta$ protects from dephosphorylation and stabilizes lipid kinase activity. J Cell Sci 119:3613-21.

Healy DG, Falchi M, O'Sullivan SS, Bonifati V, Durr A, Bressman S, and others. 2008a. Phenotype, genotype, and worldwide genetic penetrance of LRRK2-associated Parkinson's disease: a case-control study. Lancet Neurol 7:583-90.

Healy DG, Wood NW, Schapira AHV. 2008b. Test for LRRK2 mutations in patients with Parkinson's disease. Pract Neurol 8:381-5.

Heckman MG, Soto-Ortolaza AI, Aasly JO, Abahuni N, Annesi G, Bacon JA, and others. 2013. Population-specific frequencies for LRRK2 susceptibility variants in the genetic epidemiology of Parkinson's disease (GEO-PD) consortium. Mov Disord 28:1740-4.

Henderson JL, Kormos BL, Hayward MM, Coffman KJ, Jasti J, Kurumbail RG, and others. 2015. Discovery and preclinical profiling of 3-[4-(morpholin-4-yl)-7H-pyrrolo[2,3-d] pyrimidin-5-yl]benzonitrile (PF-06447475), a highly potent, selective, brain penetrant, and in vivo active LRRK2 kinase inhibitor. J Med Chem 58:419-32.

Hermanson SB, Carlson CB, Riddle SM, Zhao J, Vogel KW, Nichols RJ, and others. 2012. Screening for novel LRRK2 inhibitors using a high-throughput TR-FRET cellular assay for LRRK2 Ser935 phosphorylation. PLoS One 7:e43580.

Herzig MC, Kolly C, Persohn E, Theil D, Schweizer T, Hafner T, and others. 2011. LRRK2 protein levels are determined by kinase function and are crucial for kidney and lung homeostasis in mice. Hum Mol Genet 20:4209-23.

Hongge L, Kexin G, Xiaojie M, Nian X, Jinsha H. 2015. The role of LRRK2 in the regulation of monocyte adhesion to endothelial cells. J Mol Neurosci 55:233-9.

Ishihara L, Warren L, Gibson R, Amouri R, Lesage S, Durr A, and others. 2006. Clinical features of Parkinson disease patients with homozygous leucine-rich repeat kinase 2 G2019S mutations. Arch Neurol 63:1250-4.

Ito G, Fujimoto T, Kamikawaji S, Kuwahara T, Iwatsubo T. 2014. Lack of correlation between the kinase activity of LRRK2 harboring kinase-modifying mutations and its phosphorylation at Ser910, 935, and Ser955. PLoS One 9:e97988.

Ito G, Okai T, Fujino G, Takeda K, Ichijo H, Katada T, and others. 2007. GTP binding is essential to the protein kinase activity of LRRK2, a causative gene product for familial Parkinson's disease. Biochemistry 46:1380-8.

Jaleel M, Nichols RJ, Deak M, Campbell DG, Gillardon F, Knebel A, and others. 2007. LRRK2 phosphorylates moesin at threonine-558: characterization of how Parkinson's disease mutants affect kinase activity. Biochem J 405:30717.

Jorgensen ND, Peng Y, Ho CC-Y, Rideout HJ, Petrey D, Liu $\mathrm{P}$, and others. 2009. The WD40 domain is required for LRRK2 neurotoxicity. PLoS One 4:e8463.

Kethiri RR, Bakthavatchalam R. 2014. Leucine-rich repeat kinase 2 inhibitors: a review of recent patents (2011-2013). Expert Opin Ther Pat 24:745-57. 
Kett LR, Boassa D, Ho CC-Y, Rideout HJ, Hu J, Terada M, and others. 2012. LRRK2 Parkinson disease mutations enhance its microtubule association. Hum Mol Genet 21:890-9.

Kim B, Yang M, Choi D, Kim J, Kim H, Seol W, and others. 2012. Impaired inflammatory responses in murine Lrrk2knockdown brain microglia. PLoS One 7:e34693.

Kubo M, Kamiya Y, Nagashima R, Maekawa T, Eshima K, Azuma S, and others. 2010. LRRK2 is expressed in B-2 but not in B-1 B cells, and downregulated by cellular activation. J Neuroimmunol 229:123-8.

Kuss M, Adamopoulou E, Kahle PJ. 2014. Interferon- $\gamma$ induces leucine-rich repeat kinase LRRK2 via extracellular signalregulated kinase ERK5 in macrophages. J Neurochem 129:980-7.

Kuwahara T, Inoue K, D'Agati VD, Fujimoto T, Eguchi T, Saha S, and others. 2016. LRRK2 and RAB7L1 coordinately regulate axonal morphology and lysosome integrity in diverse cellular contexts. Sci Rep 6:29945.

Lang AE, Lozano AM. 1998. Parkinson's disease-first of two parts. N Engl J Med 339:1044-53.

Lavalley NJ, Slone SR, Ding H, West AB, Yacoubian TA. 2016. 14-3-3 Proteins regulate mutant LRRK2 kinase activity and neurite shortening. Hum Mol Genet 25:109-22.

Lee BD, Shin J-H, VanKampen J, Petrucelli L, West AB, Ko HS, and others. 2010a. Inhibitors of leucine-rich repeat kinase-2 protect against models of Parkinson's disease. Nat Med 6:998-1000.

Lee H, James WS, Cowley SA. 2017. LRRK2 in peripheral and central nervous system innate immunity: its link to Parkinson's disease. Biochem Soc Trans 45:131-9.

Lee S, Liu H-P, Lin W-Y, Guo H, Lu B. 2010b. LRRK2 kinase regulates synaptic morphology through distinct substrates at the presynaptic and postsynaptic compartments of the Drosophila neuromuscular junction. J Neurosci 30:16959-69.

Lesage S, Dürr A, Tazir M, Lohmann E, Leutenegger A-L, Janin S, and others. 2006. LRRK2 G2019S as a cause of Parkinson's disease in North African Arabs. N Engl J Med 354:422-3.

Li K, Tang B, Liu Z, Kang J, Zhang Y, Shen L, and others. 2015. LRRK2 A419V variant is a risk factor for Parkinson's disease in Asian population. Neurobiol Aging 36:2908.e112908.e15.

Li X, Wang QJ, Pan N, Lee S, Zhao Y, Chait BT, and others. 2011. Phosphorylation-dependent 14-3-3 binding to LRRK2 is impaired by common mutations of familial Parkinson's disease. PLoS One 6:e17153.

Lill CM, Roehr JT, McQueen MB, Kavvoura FK, Bagade S, Schjeide B-MM, and others. 2012. Comprehensive research synopsis and systematic meta-analyses in Parkinson's disease genetics: the PDGene Database. PLoS Genet 8:e1002548.

Lin X, Parisiadou L, Gu X-L, Wang L, Shim H, Sun L, and others. 2009. Leucine-rich repeat kinase 2 regulates the progression of neuropathology induced by Parkinson'sdisease-related mutant $\alpha$-synuclein. Neuron 64:807-27.

Liu Z, Bryant N, Kumaran R, Beilina A, Abeliovich A, Cookson MR, and others. 2018. LRRK2 phosphorylates membranebound Rabs and is activated by GTP-bound Rab7L1 to promote recruitment to the trans-Golgi network. Hum Mol Genet 27:385-95.
Liu Z, Lee J, Krummey S, Lu W, Cai H, Lenardo MJ. 2011. The kinase LRRK2 is a regulator of the transcription factor NFAT that modulates the severity of inflammatory bowel disease. Nat Immunol 12:1063-70.

Lobbestael E, Baekelandt V, Taymans J-M. 2012. Phosphorylation of LRRK2: from kinase to substrate. Biochem Soc Trans 40:1102-10.

Lobbestael E, Civiero L, De Wit T, Taymans J-M, Greggio E, Baekelandt V. 2016. Pharmacological LRRK2 kinase inhibition induces LRRK2 protein destabilization and proteasomal degradation. Sci Rep 6:33897.

Lobbestael E, Zhao J, Rudenko IN, Beylina A, Gao F, Wetter J, and others. 2013. Identification of protein phosphatase 1 as a regulator of the LRRK2 phosphorylation cycle. Biochem J 456:119-28.

Longo F, Mercatelli D, Novello S, Arcuri L, Brugnoli A, Vincenzi F, and others. 2017. Age-dependent dopamine transporter dysfunction and serine 129 phospho- $\alpha$-synuclein overload in G2019S LRRK2 mice. Acta Neuropathol Commun 5:22.

Ma B, Xu L, Pan X, Sun L, Ding J, Xie C, and others. 2016. LRRK2 modulates microglial activity through regulation of chemokine (C-X3-C) receptor 1-mediated signalling pathways. Hum Mol Genet 25:3515-23.

MacLeod DA, Rhinn H, Kuwahara T, Zolin A, Di Paolo G, McCabe BD, and others. 2013. RAB7L1 interacts with LRRK2 to modify intraneuronal protein sorting and Parkinson's disease risk. Neuron 77:425-39.

Mamais A, Chia R, Beilina A, Hauser DN, Hall C, Lewis PA, and others. 2014. Arsenite stress down-regulates phosphorylation and 14-3-3 binding of leucine-rich repeat kinase 2 (LRRK2), promoting self-association and cellular redistribution. J Biol Chem 289:21386-400.

Manzoni C. 2017. The LRRK2-macroautophagy axis and its relevance to Parkinson's disease. Biochem Soc Trans 45:155-62.

Mata IF, Davis MY, Lopez AN, Dorschner MO, Martinez E, Yearout D, and others. 2016. The discovery of LRRK2 p.R1441S, a novel mutation for Parkinson's disease, adds to the complexity of a mutational hotspot. Am J Med Genet B Neuropsychiatr Genet 171:925-30.

Mata IF, Wedemeyer WJ, Farrer MJ, Taylor JP, Gallo KA. 2006. LRRK2 in Parkinson's disease: protein domains and functional insights. Trends Neurosci 29:286-93.

Moehle MS, Daher JPL, Hull TD, Boddu R, Abdelmotilib HA, Mobley J, and others. 2015. The G2019S LRRK2 mutation increases myeloid cell chemotactic responses and enhances LRRK2 binding to actin-regulatory proteins. Hum Mol Genet 24:4250-67.

Moehle MS, Webber PJ, Tse T, Sukar N, Standaert DG, DeSilva TM, and others. 2012. LRRK2 inhibition attenuates microglial inflammatory responses. J Neurosci 32:1602-11.

Mogi M, Harada M, Riederer P, Narabayashi H, Fujita K, Nagatsu T. 1994. Tumor necrosis factor-alpha (TNF-alpha) increases both in the brain and in the cerebrospinal fluid from parkinsonian patients. Neurosci Lett 165:208-10.

Mogi M, Harada M, Narabayashi H, Inagaki H, Minami M. 1996. Interleukin (IL)-1b, IL-2, IL-4, IL-6 and transforming growth factor-a levels are elevated in ventricular 
cerebrospinal fluid in juvenile parkinsonism and Parkinson's disease. Neurosci Lett 211:13-6.

Muda K, Bertinetti D, Gesellchen F, Hermann JS, von Zweydorf F, Geerlof A, and others. 2014. Parkinson-related LRRK2 mutation $\mathrm{R} 1441 \mathrm{C} / \mathrm{G} / \mathrm{H}$ impairs PKA phosphorylation of LRRK2 and disrupts its interaction with 14-3-3. Proc Natl Acad Sci U S A 111:E34-43.

Nalls MA, Pankratz N, Lill CM, Do CB, Hernandez DG, Saad M, and others. 2014. Large-scale meta-analysis of genome-wide association data identifies six new risk loci for Parkinson's disease. Nat Genet 46:989-93.

Nichols RJ, Dzamko N, Hutti JE, Cantley LC, Deak M, Moran J, and others. 2009. Substrate specificity and inhibitors of LRRK2, a protein kinase mutated in Parkinson's disease. Biochem J 424:47-60.

Nichols RJ, Dzamko N, Morrice NA, Campbell DG, Deak M, Ordureau A, and others. 2010. 14-3-3 binding to LRRK2 is disrupted by multiple Parkinson's disease-associated mutations and regulates cytoplasmic localization. Biochem J 430:393-404.

Ohta E, Katayama Y, Kawakami F, Yamamoto M, Tajima K, Maekawa T, and others. 2009. I2020T leucine-rich repeat kinase 2, the causative mutant molecule of familial Parkinson's disease, has a higher intracellular degradation rate than the wild-type molecule. Biochem Biophys Res Commun 390:710-5.

Orenstein SJ, Kuo S-H, Tasset I, Arias E, Koga H, FernandezCarasa I, and others. 2013. Interplay of LRRK2 with chaperone-mediated autophagy. Nat Neurosci 16:394-406.

Ostrerova N, Petrucelli L, Farrer M, Mehta N, Choi P, Hardy J, and others. 1999. $\alpha$-Synuclein shares physical and functional homology with 14-3-3 proteins. J Neurosci 19:578291.

Ozelius LJ, Senthil G, Saunders-Pullman R, Ohmann E, Deligtisch A, Tagliati M, and others. 2006. LRRK2 G2019S as a cause of Parkinson's disease in Ashkenazi Jews. N Engl J Med 354:424-5.

Paisán-Ruíz C, Jain S, Evans EW, Gilks WP, Simón J, van der Brug M, and others. 2004. Cloning of the gene containing mutations that cause PARK8-linked Parkinson's disease. Neuron 44:595-600.

Papapetropoulos S, Singer C, Ross OA, Toft M, Johnson JL, Farrer MJ, and others. 2006. Clinical heterogeneity of the LRRK2 G2019S mutation. Arch Neurol 63:1242-6.

Pihlstrøm L, Rengmark A, Bjørnarå KA, Dizdar N, Fardell C, Forsgren L, and others. 2015. Fine mapping and resequencing of the PARK16 locus in Parkinson's disease. J Hum Genet 60:357-62.

Plotegher N, Kumar D, Tessari I, Brucale M, Munari F, Tosatto L, and others. 2014. The chaperone-like protein 14-3-3 h interacts with human a-synuclein aggregation intermediates rerouting the amyloidogenic pathway and reducing $\alpha$-synuclein cellular toxicity. Hum Mol Genet 23:5615-29.

Poewe W. 2008. Non-motor symptoms in Parkinson's disease. Eur J Neurol 15:14-20.

Polymeropoulos MH, Lavedan C, Leroy E, Ide SE, Dehejia A, Dutra A, and others. 1997. Mutations in the $\alpha$-synuclein gene identified in families with Parkinson's disease. Science 276:2045-7.
Porter GW, Khuri FR, Fu H. 2006. Dynamic 14-3-3/client protein interactions integrate survival and apoptotic pathways. Semin Cancer Biol 16:193-202.

Pungaliya PP, Bai Y, Lipinski K, Anand VS, Sen S, Brown EL, and others. 2010. Identification and characterization of a leucine-rich repeat kinase 2 (LRRK2) consensus phosphorylation motif. PLoS One 5:e13672.

Purlyte E, Dhekne HS, Sarhan AR, Gomez R, Lis P, Wightman M, and others. 2018. Rab29 activation of the Parkinson's disease-associated LRRK2 kinase. EMBO J 37:1-18.

Reyniers L, Del Giudice MG, Civiero L, Belluzzi E, Lobbestael E, Beilina A, and others. 2014. Differential protein-protein interactions of LRRK1 and LRRK2 indicate roles in distinct cellular signalling pathways. J Neurochem 131:239-50.

Reynolds A, Doggett EA, Riddle SM, Lebakken CS, Nichols RJ. 2014. LRRK2 kinase activity and biology are not uniformly predicted by its autophosphorylation and cellular phosphorylation site status. Front Mol Neurosci 7:54.

Ross OA, Soto-Ortolaza AI, Heckman MG, Aasly JO, Abahuni N, Annesi G, and others. 2011. Association of LRRK2 exonic variants with susceptibility to Parkinson's disease: a case-control study. Lancet Neurol 10:898-908.

Ross OA, Wu Y-R, Lee M-C, Funayama M, Chen M-L, Soto AI, and others. 2008. Analysis of LRRK2 R1628P as a risk factor for Parkinson's disease. Ann Neurol 64:88-92.

Rudenko IN, Kaganovich A, Hauser DN, Beylina A, Chia R, Ding J, and others. 2012. The G2385R variant of leucinerich repeat kinase 2 associated with Parkinson's disease is a partial loss-of-function mutation. Biochem J 446:99-111.

Rudenko IN, Kaganovich A, Langston RG, Beilina A, Ndukwe K, Kumaran R, and others. 2017. The G2385R risk factor for Parkinson's disease enhances CHIP-dependent intracellular degradation of LRRK2. Biochem J 474:1547-58.

Russo I, Berti G, Plotegher N, Bernardo G, Filograna R, Bubacco L, and others. 2015. Leucine-rich repeat kinase 2 positively regulates inflammation and down-regulates NF- $\mathrm{BB}$ p50 signaling in cultured microglia cells. J Neuroinflammation 12:230.

Satake W, Nakabayashi Y, Mizuta I, Hirota Y, Ito C, Kubo M, and others. 2009. Genome-wide association study identifies common variants at four loci as genetic risk factors for Parkinson's disease. Nat Genet 41:1303-7.

Sato S, Chiba T, Sakata E, Kato K, Mizuno Y, Hattori N, and others. 2006. 14-3-3 $\mathrm{g}$ is a novel regulator of parkin ubiquitin ligase. EMBO J 25:211-21.

Schapansky J, Nardozzi JD, Felizia F, LaVoie MJ. 2014. Membrane recruitment of endogenous LRRK2 precedes its potent regulation of autophagy. Hum Mol Genet 23:420114.

Sen S, Webber PJ, West AB. 2009. Dependence of leucine-rich repeat kinase 2 (LRRK2) kinase activity on dimerization. J Biol Chem 284:36346-56.

Sheng Z, Zhang S, Bustos D, Kleinheinz T, Le Pichon CE, Dominguez SL, and others. 2012. Ser1292 autophosphorylation is an indicator of LRRK2 kinase activity and contributes to the cellular effects of PD mutations. Sci Transl Med 4:164ra161.

Sidransky E, Lopez G. 2012. The link between the GBA gene and parkinsonism. Lancet Neurol 11:986-998. 
Simón-Sánchez J, Schulte C, Bras JM, Sharma M, Gibbs JR, Berg D, and others. 2009. Genome-wide association study reveals genetic risk underlying Parkinson's disease. Nat Genet 41:1308-12.

Skibinski G, Nakamura K, Cookson MR, Finkbeiner S. 2014. Mutant LRRK2 toxicity in neurons depends on LRRK2 levels and synuclein but not kinase activity or inclusion bodies. J Neurosci 34:418-33.

Smith WW, Pei Z, Jiang H, Dawson VL, Dawson TM, Ross CA. 2006. Kinase activity of mutant LRRK2 mediates neuronal toxicity. Nat Neurosci 9:1231-3.

Smith WW, Pei Z, Jiang H, Moore DJ, Liang Y, West AB, and others. 2005. Leucine-rich repeat kinase 2 (LRRK2) interacts with parkin, and mutant LRRK2 induces neuronal degeneration. Proc Natl Acad Sci U S A 102:18676-81.

Steger M, Diez F, Dhekne HS, Lis P, Nirujogi RS, Karayel O, and others. 2017. Systematic proteomic analysis of LRRK2-mediated Rab GTPase phosphorylation establishes a connection to ciliogenesis. Elife 6:e31012.

Steger M, Tonelli F, Ito G, Davies P, Trost M, Vetter M, and others. 2016. Phosphoproteomics reveals that Parkinson's disease kinase LRRK2 regulates a subset of Rab GTPases. Elife 5:e12813.

Su X, Federoff HJ. 2014. Immune responses in Parkinson's disease: interplay between central and peripheral immune systems. Biomed Res Int 2014:275178.

Sulzer D, Alcalay RN, Garretti F, Cote L, Kanter E, AginLiebes J, and others. 2017. T cells from patients with Parkinson's disease recognize $\alpha$-synuclein peptides. Nature 546:656-61.

Tan E-K, Peng R, Teo Y-Y, Tan LC, Angeles D, Ho P, and others. 2010. Multiple LRRK2 variants modulate risk of Parkinson disease: a Chinese multicenter study. Hum Mutat 31:561-8.

Thévenet J, Pescini Gobert R, Hooft van Huijsduijnen R, Wiessner C, Sagot YJ. 2011. Regulation of LRRK2 expression points to a functional role in human monocyte maturation. PLoS One 6:e21519.

Thomas B, Beal MF. 2007. Parkinson's disease. Hum Mol Genet 16:R183-94.

Ubl A, Berg D, Holzmann C, Krüger R, Berger K, Arzberger T, and others. 2002. 14-3-3 protein is a component of Lewy bodies in Parkinson's disease-mutation analysis and association studies of 14-3-3 eta. Brain Res Mol Brain Res 108:33-9.
Vancraenenbroeck R, De Raeymaecker J, Lobbestael E, Gao F, De Maeyer M, Voet A, and others. 2014. In silico, in vitro and cellular analysis with a kinome-wide inhibitor panel correlates cellular LRRK2 dephosphorylation to inhibitor activity on LRRK2. Front Mol Neurosci 7:51.

Wandu WS, Tan C, Ogbeifun O, Vistica BP, Shi G, Hinshaw $\mathrm{SJH}$, and others. 2015. Leucine-rich repeat kinase 2 (Lrrk2) deficiency diminishes the development of experimental autoimmune uveitis (EAU) and the adaptive immune response. PLoS One 10:e018906.

Wang B, Abraham N, Gao G, Yang Q. 2016. Dysregulation of autophagy and mitochondrial function in Parkinson's disease. Transl Neurodegener 5:19.

Wang L, Xie C, Greggio E, Parisiadou L, Shim H, Sun L, and others. 2008. The chaperone activity of heat shock protein 90 is critical for maintaining the stability of leucine-rich repeat kinase 2. J Neurosci 28:3384-91.

Webber PJ, Smith AD, Sen S, Renfrow MB, Mobley JA, West AB. 2011. Autophosphorylation in the leucine-rich repeat kinase 2 (LRRK2) GTPase domain modifies kinase and GTP-binding activities. J Mol Biol 412:94-110.

West AB, Moore DJ, Biskup S, Bugayenko A, Smith WW, Ross CA, and others. 2005. Parkinson's disease-associated mutations in leucine-rich repeat kinase 2 augment kinase activity. Proc Natl Acad Sci U S A 102:16842-7.

Yacoubian TA, Slone SR, Harrington AJ, Hamamichi S, Schieltz JM, Caldwell KA, and others. 2010. Differential neuroprotective effects of 14-3-3 proteins in models of Parkinson's disease. Cell Death Dis 1:e2.

Yao C, Johnson WM, Gao Y, Wang W, Zhang J, Deak M, and others. 2013. Kinase inhibitors arrest neurodegeneration in cell and C. elegans models of LRRK2 toxicity. Hum Mol Genet 22:328-44.

Zhao HT, John N, Delic V, Ikeda-Lee K, Kim A, Weihofen A, and others. 2017. LRRK2 antisense oligonucleotides ameliorate $\alpha$-synuclein inclusion formation in a Parkinson's disease mouse model. Mol Ther Nucleic Acids 8:508-19.

Zhao J, Molitor TP, Langston JW, Nichols RJ. 2015. LRRK2 dephosphorylation increases its ubiquitination. Biochem J 469:107-20.

Zimprich A, Biskup S, Leitner P, Lichtner P, Farrer M, Lincoln S, and others. 2004. Mutations in LRRK2 cause autosomal-dominant Parkinsonism with pleomorphic pathology. Neuron 44:601-7. 